\title{
PLANETARY CARTOGRAPHY AND MAPPING: WHERE WE ARE TODAY, AND WHERE WE ARE HEADING FOR?
}

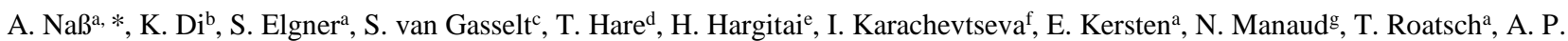 \\ Rossi $^{\text {h }}$, J. Skinner, Jr. ${ }^{\mathrm{d}}$, and M. Wählisch ${ }^{\mathrm{a}}$

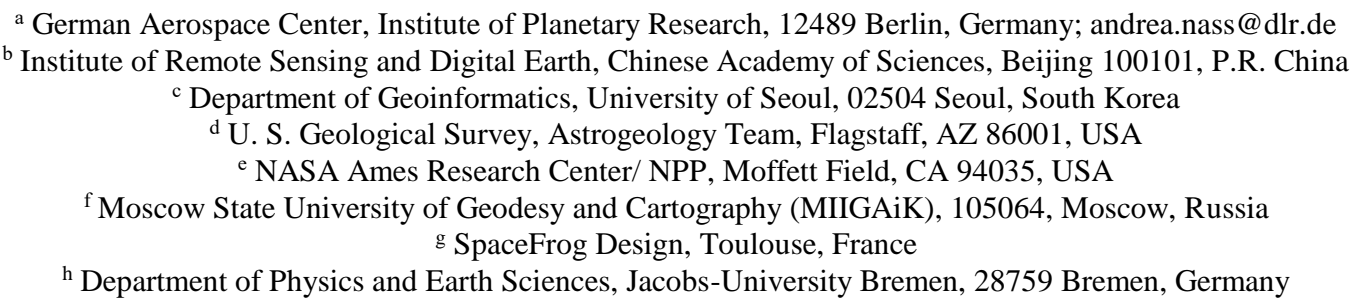

Commission III, ICWG III/II

KEY WORDS: maps, cartography, planetary science, GIS, sustainability

\begin{abstract}
:
Planetary Cartography does not only provides the basis to support planning (e.g., landing-site selection, orbital observations, traverse planning) and to facilitate mission conduct during the lifetime of a mission (e.g., observation tracking and hazard avoidance). It also provides the means to create science products after successful termination of a planetary mission by distilling data into maps. After a mission's lifetime, data and higher level products like mosaics and digital terrain models (DTMs) are stored in archives - and eventually into maps and higher-level data products - to form a basis for research and for new scientific and engineering studies. The complexity of such tasks increases with every new dataset that has been put on this stack of information, and in the same way as the complexity of autonomous probes increases, also tools that support these challenges require new levels of sophistication. In planetary science, cartography and mapping have a history dating back to the roots of telescopic space exploration and are now facing new technological and organizational challenges with the rise of new missions, new global initiatives, organizations and opening research markets. The focus of this contribution is to summarize recent activities in Planetary Cartography, highlighting current issues the community is facing to derive the future opportunities in this field. By this we would like to invite cartographers/researchers to join this community and to start thinking about how we can jointly solve some of these challenges.
\end{abstract}

\section{INTRODUCTION AND OVERVIEW}

\subsection{Introduction}

As of today, hundreds of planetary maps have been produced and published during a number of different framework programs and projects. Therein, different mapping efforts exist, either on a national level or as collaboration between groups participating as investigators in mapping missions. However, coordination of such tasks does not end with the compilation and publication of a set of maps. Coordination may be considered successfully only when mapping products have been provided to upcoming generations of researchers and mappers to allow efficient re-use of a new sustainable data basis. In order to accomplish this, mapping infrastructure, workflows, communication paths and validation tools have to be developed and made available. In planetary context, planetary cartography is part of the even broader framework of "planetary spatial infrastructure". Related work covering the status of planetary cartography is described by Pędzich and Latuszek (2014), Kirk (2016), Williams (2016), Radebaugh et al. (2017), Nass et al. (2017), and Laura (2017).

The focus of this brief contribution is to summarize the history and recent activities in Planetary Cartography across the globe and to highlight some of the issues and opportunities the community is currently facing.

\subsection{Definition and Background}

The definitions of Cartography and maps have changed in the last fifty years. This was and is mainly pushed by the increasing developments in information and computer technology. A great overview how the terms were changed during the time is given in Kraak and Fabrikant (2017). The most recent one describes cartography as the "art, science and technology of making and using maps" (Strategic plan 2003-2011 of the International Cartographic Association, http://icaci.org/strategic-plan/), and a map as "visual representation of an environment" (Kraak and Fabrikant, 2017, p. 6). Thus, maps are one of the most important tools for communicating geospatial information between producers and receivers. Geospatial data, tools, contributions in geospatial sciences, and the communication of information and transmission of knowledge are matter of ongoing cartographic research. This applies to all topics and objects located on Earth or on any other body in our Solar System.

Visualization of data in general, and visualization of research data in particular, represents a simplified view of the real world,

\footnotetext{
* Corresponding author. This is useful to know for communication with the appropriate person in cases with more than one author.
} 
covering complex situations as well as the relationship between these (e.g. Ware, 2004; Mazza, 2009). The process to accomplish this can be divided into four major parts: (1) data pre-processing and transformation, (2) visual mapping, (3) generation of views, and (4) perception/cognition. The mapping process in Planetary Cartography is comparable to established processes commonly employed in terrestrial cartographic workflows that are described as so-called visualization pipeline (e.g., Haber and McNabb, 1990; Carpendale, 2003, Figure 1).

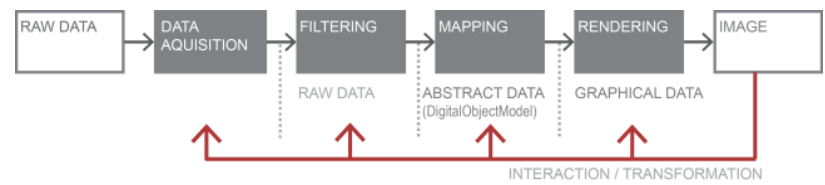

Figure 1 Visualization Pipeline

(cf. Haber and McNabb, 1990; Carpendale, 2003)

This workflow distinguishes clearly parallels to the datainformation-knowledge-wisdom hierarchy (e.g. Ackoff, 1989), taking part in the field of information sciences and knowledge management. More recent discussions about this are shown e.g. in Rowley (2007).

\subsection{History of Planetary Exploration}

Extraterrestrial mapping dates back to shortly after the invention of the telescope at the beginning of the 17 th century which marked a milestone in planetary exploration. These maps of the Moon (van Langren in 1645, Hevelius in 1647, Grimaldi and Riccioli in 1651) offered different approaches in visual and toponymic representation of an extraterrestrial landscape. Many improvements were introduced during the upcoming centuries and extraterrestrial mapping became a scientific discipline with map products similar in appearance and style as their terrestrial counterparts (Blagg and Müller, 1935; Sadler, 1962; Whitaker et al., 1963; Slipher, 1962; Mason and Hackman, 1961; Shoemaker, 1961; Portee, 2013). Despite this success and many advances in the field of Earth-based telescopic observations and mapping, detailed topographic features and landforms could only be mapped from observation platforms located on spacecraft. This process started with the first set of pictures received from the far side of the Moon (Luna 3; Babarashov et al., 1960), and Mars (Mariner 6; Davies et al., 1970). Venus was first mapped in detail by the Venera probes and results were published as a series of 27 map sheets (GUGK, 1988) and the first comprehensive cartographic atlas of multiple Solar System bodies was published by Shingareva et al. (1992). China joined the countries with planetary mapping centers with the publication of several maps, atlases and globes using the images from the Chinese Chang'E lunar probe series (e.g., Compiling Committee, 2010). Global topographic data of variable resolution are now available from laser and radar altimetry, stereo photogrammetry, stereo photoclinometry for Mercury, Venus, the Moon, Mars, Ceres, Vesta, Titan, and Phobos. Following the long-employed method of replicating images using hand drawing maps showing the topography of planets and moons used airbrush technique and manual interpretation of several sets of photographs. This was replaced by digital image mosaicking techniques in the 1990s. Parallel to terrestrial developments since middle 1990 modern and digital mapping techniques within vector- and raster-based graphic software arose. This includes the first efforts of GIS-based data integration and mapping in planetary sciences. Since then, a few developments and approaches came up to make the usage of GI technologies more efficient for planetary mapping and cartography representation (e.g., Hare and Tanaka, 2001; Hare et al., 2009; van Gasselt and Nass, 2011; Nass et al., 2011; Frigeri et al., 2011; Hare et al., 2015).

The most comprehensive review on all aspects of planetary cartography was published by Snyder (1982, 1987), and Greeley and Batson (1990). Radar mapping techniques are discussed in Ford et al. (1993). For detailed summaries on the development and evolution of Planetary Cartography the reader is referred to Shevchenko et al. (2016) for the history of Soviet and Russian planetary cartography, and to Jin (2014) for Chinese Lunar mapping results. History of planetary mapping is discussed in e.g., Kopal and Carder (1974) and Morton (2002), and recent planetary cartographic techniques and tools are reviewed in Beyer (2015) and Hare et al. (2017, in prep.).

\section{ASSOCIATED SCIENCE CENTERS, INSTITUTES, AND GROUPS}

Planetary Cartography has found its manifestation in governmental activities, community efforts, professional organizations, and, in recent years, private activities. That activity substantiated with the revival of planetary exploration in the early 2000s when Europe visited the Moon for the first time, and the US launched a number of exploration missions. With the success of Asian spacecraft missions to the Moon and Mars joining the global planetary exploration endeavour, Planetary Cartography is increasingly becoming a global collaborative effort with Planetary Mapping being one of its main tools to accomplish the goals.

This chapter introduces institutes and groups working in the field of Planetary Cartography and Mapping. Some of them have a long history in planetary cartography while others represent more recent efforts. Their activities are usually organized on a national level but they are internationally related to each other through research cooperation and collaborative projects. This overview does not qualify to be complete and to list all active organizations and groups. It should provide a cross-section covering main institutions as well as groups and initiatives.

\subsection{Institutes and Facilities}

In the United States, the Astrogeology Science Center (ACS) was established in Flagstaff, Arizona on July 1, 1963 as a research facility of the United State Geological Survey (USGS) (Schaber 2005) through the efforts and requests of several geoscientists and cartographers, perhaps most notably geologist E. Shoemaker. The USGS and the NASA agreed on the benefits of a research center that focused on compiling planetary maps, developing observational instrumentation, and training both astronauts and fellow researchers. Therein, location in Flagstaff proved an advantageous based on existing planetary research community, proximity to lunar-observing telescopes, as well as geologically diverse, yet highly accessible analog terrain. The USGS ASC has evolved over the past five decades in response not only to the changing needs of NASA and the planetary science community but also to the increased volume and diversity of modern, technologically advanced data sets acquired for planetary bodies. By doing so, within the Planetary Geological Mapping Program (1) (founded by NASA and coordinated by the USGS ACS) planetary maps and cartographic products were produced which reveal topography, geology, topology, image mosaics, and more. The aim of this program is to support the international research community with

\footnotetext{
${ }^{(1)}$ For more information see http://planetarymapping.wr.usgs.gov/
} 
high-quality peer-reviewed geologic maps of planetary bodies. To accomplish this and to have comparable and homogenous map results, the mapping process has been standardized and is coordinated from its beginning (usability of input data) up to final map layout, printing, publishing, and archiving (Tanaka et al., 2011). All the resulted products are available to the international scientific community and the general public as a national resource ${ }^{(2)}$.

In order to handle these tasks effectively, i.e., to ensure that unnecessary duplication is reduced to a minimum, cooperation is critical, wherein multiple institutions and organizational bodies must cross collaborate. Thus, the USGS ACS established cooperation with institutions like NASA (at multiple programmatic levels), European Space Agency (ESA), and Jet Propulsion Laboratory (JPL) but also community organizations such as the International Astronomical Union (IAU) and the more recently formed Mapping and Planetary Spatial Infrastructure Team (MAPSIT).

At about the same time, in 1961, the Moscow State University of Geodesy and Cartography (MIIGAiK) established its Fundamental Research Laboratory at the Department of Aerial Photo Surveying. The laboratory focused on lunar image processing and mapping. In 1968, a new institute was officially founded: the Space Research Institute of the Academy of Sciences of the USSR (IKI). Since 1999 MIIGAiK, Dresden Technical University (Germany), Eötvös Loránd University (ELTE) (Hungary), and the University of Western Ontario (Canada) have participated in the project Multi-language Maps of Planets and their Moons (Shingareva et al., 2005). Intense international collaborations in the course of ESA's Mars Express have resulted in Phobos special issue (Oberst et al., 2014) and The Phobos Altas (Savinykh et al., 2015).

Nowadays, the MIIGAiK Extraterrestrial Laboratory (MExLab) is focusing on planetary geodesy and GIS-based cartography methods for Solar System bodies (Karachevtseva et al., 2016; Shevchenko, 2016). Research topics include fundamental parameters of celestial bodies such as shape, rotational parameters, and forced librations as well as planetary coordinate systems. A variety of wall maps of Phobos (Karachevtseva et al., 2015) and a map and globe of Mercury have also been published recently. One of the research branches is devoted to cartographic support for Russian landing site selection for future missions (Luna-25, 27-28) as well as planning of future orbital mission to the Moon (Luna-26). Using modern spatial and web-based technology MExLab stores results of these studies in their planetary geodatabase with web-access provided via its geoportal ${ }^{(3)}$.

Planetary mapping, including morphologic study of craters and work on planetary nomenclature localization in Russian is also the domain of the Department of Lunar and Planetary Physics of Sternberg Astronomical Institute (SAI), and a number of collaborations have substantiated in this national context (e.g., Shevchenko et al., 2016).

In Germany, the Institute of Planetary Research at the German Aerospace Center (DLR) in Berlin - among other groups in Germany - has been involved in a number of planetary cartographic topics since its establishment in the early 1990s. A series of Mars maps were compiled in the early 1990s (Hiller et al., 1993; Neugebauer and Dorrer, 1996) in preparation of the Russian Mars-96 mission. Since that time the main focus of DLR's cartography has been put on generation of image

\footnotetext{
${ }^{(2)} \mathrm{http}: / /$ astrogeology.usgs.gov/.

${ }^{\text {(3) }} \mathrm{http}: / /$ cartsrv.mexlab.ru/geoportal.
}

mosaics and topographic maps. For the HRSC contribution for Mars Express (Jaumann et al., 2007) this work has been conducted also in close collaboration with groups at universities like the TU of Berlin, FU Berlin, TU Dresden, TU Munich or University Hannover. It involves production of image and topographic maps, definition of a large-scale quadrangle schema for cartographic representation of Mars (Lehmann et al., 1997; Albertz et al., 2005), or automatization of map generation processes (PIMap, Gehrke et al., 2006). A new set of cartographic products based on the integration of data from multiple orbits was produced and published recently (Gwinner, et al., 2016). Controlled images and ortho-image mosaics were also produced and published for Phobos (Wählisch et al., 2010, 2014; Willner et al., 2010, 2014), or the Icy Saturnian Satellites (4) (Roatsch et al., 2009). For Ceres and Vesta, global mosaics serve as base map for different atlas collections ${ }^{(5)}$ (e.g. Roatsch et al. 2013, 2016).

During the last ten years the DLR has also been focusing on GIS-based mapping and tasks of processing, analyzing, archiving, and visualizing scientific results (e.g., Deuchler et al., 2004; Saiger et al., 2005). Topics of interests also include standardized cartographic visualization of scientific map results in order to create homogenous and comparable maps and data archiving prodcuts (e.g., van Gasselt and Nass 2011, Nass et al., 2011). To provide sophisticated user experiences, which satisfies scientific as well as public outreach purposes, first steps have been undertaken to set up WebMap Services and WebGL applications by using image data and maps from the Apollo-17 and LRO missions (Clever,2014; Maslonka, 2014).

Driven by China's Lunar exploration missions, Chang' $E-1$, Chang' $E-2$, and Chang' $E-3$, lunar cartography work has been undertaken by several institutions of the Chinese Academy of Sciences (CAS), including the National Astronomical Observatories of China (NAOC), Institute of Geochemistry (IGCAS), Institute of Remote Sensing and Digital Earth (RADI). NOAC established the Science and Application Center for Lunar and Deep Space Exploration in 2003. One of its major responsibilities is to produce global cartographic products from data acquired by the aforementioned Chinese lunar missions. IGCAS established the Center for Lunar and Planetary Sciences in 2005 with the focus on geological mapping using the same datasets. RADI established the Planetary Mapping and Remote Sensing laboratory in 2008. The Lab works on the development of high precision planetary mapping methods using multi-source data and has produced high-resolution topographic products of the Chang'E-3 landing site using orbital and rover images.

Some other groups in China's universities and institutions have also been involved in relevant research of planetary mapping. Many lunar topographic products have been completed: e.g., a global image mosaic (using orbiter imagery data of Chang' $E-1$; Li et al., 2010a), a global lunar digital elevation model (DEM) (using altimetry data of Chang'E-1; Ping et al., 2009; Li et al., 2010b; Hu et al., 2013), a high-resolution global DEM and ortho-image (using stereo imagery data from Chang' $E-2$; Li et al. 2015), a high resolution DEM and ortho-image map of Chang' $E-3$ landing area (by Chang' $E-2$ stereo imagery and LOLA data; Wu et al., 2014), high precision DEMs and orthoimage of the Chang' $E-3$ landing site (by the lander's descent images and the rover's stereo images; Liu et al., 2014).

\footnotetext{
(4) http://ciclops.org/maps/ and http://pds-imaging.jpl.nasa.gov/

${ }^{(5)} \mathrm{http}: / /$ dawngis.dlr.de/atlas (Dawn gis web page).
} 
As emphasized earlier, such a presentation cannot be considered complete as it only highlights some of the efforts that are being made globally. New groups in China, India and Japan and also Korea are developing fast. Other projects across the US, such as the JMARS/JVesta ${ }^{(6)}$ project led by Arizona State University (ASU), Vesta/MarsTrek (7) developed at NASA's Jet Propulsion Laboratory (JPL), playing an important role internationally. And also in Europe a number of university and research institutes work on map production and aspects of cartography and coordinate international cartographic work (e.g., ELTE, Hungary; University of Oulu, Finland; University of Muenster, Germany; University of Chieti-Pescara, or University of Perugia, Italy). With Italian key instruments on board BepiColombo observing Mercury, members of several Italian scientific centres join planetary geologic mapper's community (Galluzzi et al., 2016).

\subsection{Organizations and Initiatives}

Different groups were originated by NASA to coordinate map requirements, recommend map series and standards, establish priorities for map production, monitor map distribution, and facilitate international cooperation in lunar mapping (PCWG, 1989). The last ten years of activity within Planetary Cartography and Geologic Mapping Working Group (PCGMWG) was largely focused on monitoring and guiding the cartographic contributions of the USGS ASC.

The Mapping and Planetary Spatial Infrastructure Team (MAPSIT) was formulated in 2014 as a means to re-affirm that modern cartography i.e., spatial data infrastructure (NSF, 2012), fundamentally affects all aspects of scientific investigation and mission planning, regardless of the target body of interest. MAPSIT faces tremendous challenges, not the least of which is the sheer scope of modern planetary exploration, which results in a multitude of spatial parameters related to instrument types, target body characteristics, and coordinating institutions.

USGS ASC and ASI held a topical meeting in 2009 on the topic of "Geological Mapping of Mars: a workshop on new concepts and tools" (Pondrelli et al., 2011). Since then, the state-of-theart evolved significantly; not only from institutional (space agencies and surveys) perspective, but also in terms of technology, applications, and services. While planetary data mapping workshops have been held three times in the United States (coordinated by USGS ACS), ESA's Space Astronomy Centre (ESAC) supported its first Planetary GIS workshop in 2015 (Manaud et al., 2016b). This year the $1^{\text {st }}$ Workshop for "Planetary Mapping and Virtual Observatory" was been organized within the VESPA (Virtual European Solar and Planetary Access) program. This workshop aims at bringing together the geologic, geospatial and Virtual Observatory (VO) communities for bringing forward knowledge, tools and standards for mapping the Solar System.

Naming of topographic features and the publication of the Gazetteer of Planetary Nomenclature are coordinated by the International Astronomical Union (IAU). It was founded in 1919 at the Constitutive Assembly of the International Research Council in Brussels, Belgium to oversee assigning names for stars, planets, moons, asteroids, comets and surface features on them (Blaauw, 1994). The first goals were to normalize various systems used in Lunar and Martian nomenclatures across different countries (Blagg, 1935). The current nomenclature database is managed by the USGS ASC on behalf of the IAU.

\footnotetext{
(6) https://jmars.asu.edu/

(7) https://marstrek.jpl.nasa.gov/index.html.
}

In 1976, the IAU established a working group on the Cartographic Coordinates and Rotational Elements of Planets and Satellites to report triennially on the preferred volumes for the parameters of the rotation rate, spin axis, prime meridian, and reference surface for planets and satellites (Archinal, 2011). This working group founded to allow the consistent data usage across many facilities, including surface exploration by robots and humans. However, the IAU's oversight does not cover other standards essential for digital mapping including common feature attributions, feature symbols, recommended mapping scales and metadata or the documentation of the data. For the U.S., this role has been filled by the Federal Geographic Data Committee $(F G D C)$ and its recommendations are generally closely adopted by the International Standards Organization (ISO). Within the FGDC (2006) feature attributes and their assigned symbols for terrestrial and also planetary digital maps are defined. For a clear understanding of planetary maps, these symbols are primarily based on the same set of attributes and symbols as used for the Earth (see e.g., Nass et al., 2011; Hargitai and Shingareva 2011, Hargitai et al., 2014).

The International Society for Photogrammetry and Remote Sensing (ISPRS) working group IV/8 "Planetary Mapping and Spatial Databases" is built by the community to provide a platform for those involved in all topics of planetary cartography, such as data acquisition, processing, and information extraction from planetary remote sensing data for the mapping of celestial bodies. This also includes the evaluation and refinement of reference systems, coordinate systems, control networks, map sheet definitions, etc., and their standardization. The group organizes workshops and symposiums to exchange the developments in planetary mapping, cartography and remote sensing, and promotes international cooperation since 1998. After the 2016 ISPRS Congress in Prague the working group has transformed to a new inter-commission working group III/II "Planetary Remote Sensing and Mapping".

The Commission on Planetary Cartography of the International Cartographic Association (ICA) was established in 1995 with the goal of disseminating products and initiating outreach and professional projects in countries where planetary cartographic materials are scarcely available or altogether absent. The commission focuses on supporting planetary cartographic projects in emerging planetary communities. Since its formation, the commission developed three multilingual outreach map series: a series edited in Dresden (Buchroithner, 1999), a Central European edition (Shingareva et al., 2005), and a special series for children (Hargitai et al., 2015). The commission members compiled the Multilingual Glossary of Planetary Cartography (Shingareva and Krasnopevsteva, 2011) and the GIS-ready Integrated Database of Planetary Features (Hargitai, 2016). It also developed a planetary cartographic application that can be used to compare sizes of planetary features to countries and states (Gede and Hargitai, 2015) and maintains the Digital Museum of Planetary Mapping ${ }^{\left({ }^{8}\right)}$.

In addition to institutional and organizational efforts, a number of initiatives have arisen in recent years motivated not only by individuals but also by commercial entities that specialize in combining planetary (map) data with web technologies. Today, different startups and organizations offer platforms and preexisting cartographic databases which often feature open-source mapping technologies at their core. It has made it even easier

\footnotetext{
(8) http://planetarymapping.wordpress.com.
} 
for non-GIS-specialists, researchers, or data enthusiasts to visualize, manipulate, and share their data and maps on the web (Zastrow, 2015). E.g., CARTO, a company focused on webbased geospatial data visualization and analysis, collaborated with ESA to support an open-source outreach project intended to raise public awareness of ESA's ExoMars Rover mission through an interactive map of the candidate landing sites (Where On Mars? ${ }^{\text {(9)}}$, Manaud et al., 2015).

The OpenPlanetary ${ }^{(10)}$ initiative was created in 2015 (Manaud et al., 2016a) providing an online framework to help collaborate on common planetary mapping and data analysis problems, on new challenges, and to create new opportunities. Furthermore, it focused on building the first Open Planetary Mapping and Social platform for researchers, educators, storytellers, and the general public (Manaud et al., 2017). Also, a number of projects funded by the European Commission are directly or indirectly relevant to planetary mapping. The largest, and one of the most long-lasting efforts, is VESPA (Erard et al., 2014, 2017), the EuroPlanet H2020 Research Infrastructure component that deals with accessibility and distribution of planetary science data from very diverse scientific domains, including a specific surface mapping task (Rossi et al., 2015). E-Infrastructure projects with broad Earth Science focus, such as EarthServer-2, include a Planetary Science component, PlanetServer (Baumann et al., 2015; Rossi et al., 2016). Rather than focusing on data searches and discovery or on-demand processing, PlanetServer primarily uses the OGC WCPS standard (Baumann et al., 2010) to perform real-time data analytics (Rossi et al., 2016; Marco Figuera et al., 2015). Lastly, few citizen science projects with clear planetary mapping target exist. Some of them are embedded in a broader context, such as iMars (Muller et al., 2016); others originate from experimentdriven effort (NASA MRO HiRISE), such as PlanetFour (Aye et al., 2016), and citizen-science efforts (NASA LRO/LROC) focus on imagery mapping include Moon Zoo (Joy et al., 2011).

\section{CHALLENGES IN PLANETARY CARTOGRAPHY}

The standardization of cartographic methods and data products is critical for accurate and precise analysis and scientific reporting. This is more relevant today than ever before, as researchers have such easy access to a magnitude of digital data as well as to the tools to process and analyze these various products. The life cycle of cartographic products can be short and standardized descriptions are needed to keep track of different developments. One of our aims herein was to compartmentalize the processes of Planetary Cartography and to define, describe, and present the overall mapping process through its components' breakdown (Figure 2).

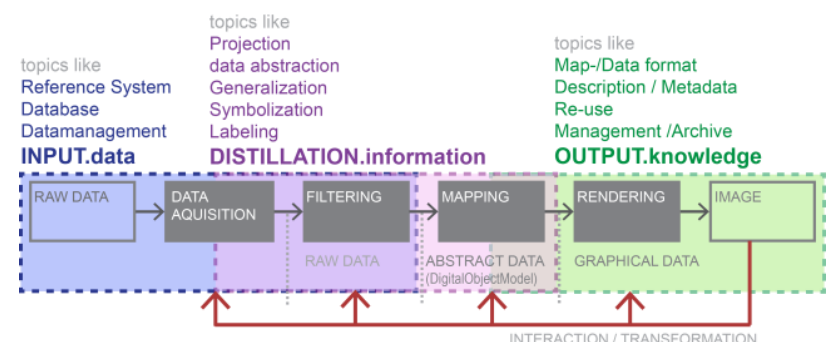

Figure 2 Visualization Pipeline linked to the process during planetary mapping and the data-information-knowledge-wisdom hierarchy (see 1.2 and Figure 1).
Processes related to the INPUT compartment (Figure 2) cover all aspects that allow not only to produce higher-level products but also to create a basis for their stable representation and reusability. One of the major future issue will be to establish an international map-data basis by digitizing analog maps and by establishing a uniform structure to describe existing data allowing them to be queried and accessed. For digital map products, a metadata description (i.e. a digital equivalent known from map legends and additional information relating to the map content), along with validation tools, and platforms capable of providing access to archiving, distribution, and querying, needs to be established. Standards already partially exist on a national level and some of the older higher-level map-data products are currently transferred to fit into such schemes. However, many unstandardized map products exist all around the world and are distributed across different institutes. One task will be to review such products and to establish a methodological repertoire to transfer maps, to establish a common metadata scheme and to provide a common semantical basis.

Within the Distillation processes (Figure 2) the core issues are the abstraction of data, the (carto)graphic visualization, and GIS-based management of derived data. We identify three major tasks that are necessary to accomplish this: (1) the definition and setup of rules and recommendations for GISbased mapping processes (cf. Tanaka et al., 2011); (2) advocating the GIS-based implementation and distribution of international cartographic symbol standards; (3) generating generic, modular data models for GIS-based mapping, which could be used by the mappers to fill in their individual mapping data, and scientific results. Currently efforts are focus on creating a template-based framework on evaluation and optimization of existing map templates. In particular, the short lifetime of products during ongoing missions pose a considerable challenge when creating such models and putting them into operational use. Furthermore, recent work focuses on revising recommendations for cartographic symbols for geologic mapping. This encompasses critical review and updating of existing standards for planetary geologic symbols (FGDC, 2006).

OUTPUT processes (Figure 2) cover all aspects of publishing and archiving mapping results in easily accessible archives and intuitive online interfaces and platforms. One method to achieve this is to incorporate already published maps along with their metadata into an internationally accessible digital map archive. This includes digitized analog maps, digital maps and mapping products in comparable formats, and builds on existing definitions that can benefit from existing validation tools. The Planetary Data System (PDS, 2009), e.g., has provided a flexible toolset to accomplish parts of this task in cooperation with USGS/ACS. Existing efforts covering this topic of metadata are described in e.g., Hare et al. (2011), Hare (2011), and Nass et al. (2010). The existing archives like e.g., the PDS/NASA, the Planetary Science Archive (PSA/ESA ${ }^{(1)}$, Besse et al., 2017), or Data Archives and Transmission System (DARTS/JAXA ${ }^{(12)}$ ) could be extended to include digital maps.

The last issue in this part covers aspects of interoperability and exchange of map projects between different mapping and database systems. As different research institutes and individuals use different tools for mapping and data storage, procedures have to be established to allow conversions and also collaborative mapping in the future. It is the ultimate goal for

\footnotetext{
(11) https://archives.esac.esa.int/psa/\#!Home\%20View.

(12) http://jda.jaxa.jp/en/.
}

\footnotetext{
(9) whereonmars.co

(10) openplanetary.co
} 
planetary geologic or other thematic maps to be produced by different groups using the same principles in data collection, analysis and display so that they are compatible.

\section{CONCLUSION AND OUTLOOK}

A general aim for this Planetary Cartography community is to develop concepts and approaches to foster future cooperation between cartographers and non-cartographers. This collaboration should focus on reducing duplication of efforts and combining limited resources in order to address technical and scientific objectives. Primarily motivated by such objectives international cross-collaborations between institutes have resently been established, providing a platform for critical discourse within organizations, as well as an constant contribution to diverse initiatives. Furthermore, these developments should focus on (1) identifying and prioritizing needs of the planetary cartography community along with a strategic timeline to accomplish such prioritized goals, (2) keeping track of ongoing work across the globe in the field of Planetary Cartography, and (3) identifying areas of evolving technologies and innovations that deal with mapping strategies as well as output media for the dissemination and communication of cartographic results.

In addition to professional and scientific applications, Planetary Cartography has sufficient data resources that would enable non-planetary cartographers to produce planetary maps for the general public. Such exploration maps are e.g. regularly produced of the ocean floors and Antarctica, but not of extraterrestrial surfaces. Professional planetary maps, typically geologic maps, are exclusively published for scientific purposes, except for a few cartographic products published by the USGS. Notably, some photomosaic maps available for the open public in multiple web platforms are not fully utilizing the cartographic tools and planetary datasets available. In short, the collaboration between the methods of cartography and the planetary science has not yet been reached its full potential. Furthermore, neither popular science books nor atlases include planetary maps, with very few exceptions, probably simply because their publishers do not know that planetary maps could be created the same way terrestrial maps are produced. The work of Planetary Cartographers should serve as a bridge between those different fields, and make this datasets available for "terrestrial cartographers" in the format they can use for producing maps for the general public.

\section{ACKNOWLEDGEMENTS (OPTIONAL)}

APR acknowledges support from the grant H2020-EINFRA-2014-2 no. 654367 (EarthServer-2) and H2020 Research Infrastructure EuroPlanet 2020 (EPN2020-RI) grant no. 654208.

IK were hosted in MIIGAiK and supported by Russian Science Foundation (project \# 14-22-00197).

\section{REFERENCES}

Ackoff, R.L., 1989. From data to wisdom. Journal of Applied Systems Analysis 16, p. 3-9.

Albertz, J., Attwenger, et al., 2005. HRSC on Mars Express Photogrammetric and Cartographic Research. In: Photogrammetric engineering and remote sensing, Vol 71, pp 1153-1160.

Archinal, B.A., A’Hearn, M.F., et al., 2011. Report of the IAU Working Group on Cartographic Coordinates and Rotational Elements: 2009, Celestial Mechanics and Dynamical Astronomy, 109, no. 2, pp 101135, doi:10.1007/s10569-010-9320-4.
Aye, K.-M., Schwamb, M.E., et al., 2016. Analysis Pipeline and Results from the PlanetFour Citizen Science Project. LPSC 2016, \#3056.

Barabashov, N.P., Mikhailov, A.A., Lipskiy, Y.N., 1960. Atlas obratnoy storony Luny. 1960. Pod redaktsiey. Moskva: Izdatelstvo Akademii nauk SSSR.

Baumann, P., 2010. The OGC Web Coverage Processing Service (WCPS) Standard. In: Geoinformatica, 14(4), pp 447-479.

Baumann, P., Mazzetti, P., et al., 2015. Big Data Analytics for Earth Sciences: the EarthServer approach. In: Int. Journal of Digital Earth, doi:10.1080/17538947.2014.1003106.

Besse, S., Vallat, C., et al., 2017. The New Planetary Science Archive (PSA): Exploration and Discovery of Scientific Datasets from ESA's Planetary Missions. LPSC 2017, \#1186.

Beyer, R.A., 2015. An introduction to the data and tools of planetary geomorphology. In: Geomorphology 240, pp 137-145.

Blaauw, A., 1994. History of IAU: the birth and first half-century of the IAU. Dordrecht: Kluwer Academic Publishers. ISBN 0-7923-2979-1.

Blagg, M.A., Müller, K., 1935. Named lunar formations. International Astronomical Union, Percy Lund, Humphries and Co Ltd, 196 p. London, GB.

Buchroithner, M.F., 1999. Mars Map: the first of the series of multilingual relief maps of terrestrial planets and their moon. ICA Conf., Ottawa, Canada.

Carpendale, M.S.T., 2003. Considering Visual Variables as a Basis for Information Visualization. Research report 2001-693-16, Dep. of Computer Science, University of Calgary, Calgary, Canada.

Clever, S., 2014. LROC - Anaglyphen vom Mond: Erstellung und Visualisierung in einem Webmapping Projekt. Ba. thesis, Beuth Hochschule für Technik Berlin.

Compiling Committee of the Chang'E-1, 2010. The Chang'E-1 Topographic Atlas of the Moon. NAOC and SinoMap Press.

Davies, M.E., Robinson, J.C., et al.,1970. Mars Chart. US Army Topographic Command, Washington, D.C., USA

Deuchler, C., Wählisch, M. et al., 2004. Combining Mars Data in GRASS GIS for Geological Mapping, ISPRS, Istanbul, Turkey.

Erard, E., Cecconi, B., et al., 2014. Planetary science virtual observatory architecture. In: Astronomy and Computing, 7, pp 71-80.

Erard, S., Cecconi, B., et al., 2017. VESPA: a community-driven Virtual Observatory in Planetary Science. In: Planetary and Space Science (PSS), in press, doi: 10.1016/j.pss.2017.05.013.

FGDC, 2006. Digital Cartographic Standard for Geologic Map Symbolization, Federal Geographic Data Committee, Document \# FGDC-STD-013-2006.

Ford, J.P., Plaut, J., et al., 1993. Guide to Magellan Image Interpretation. NASA-JPL, Pasadena, California, USA.

Frigeri, A., Hare, T., et al., 2011. A working environment for digital planetary data processing and mapping using ISIS and GRASS GIS. In: Planetary and Space Science (PSS), Vol. 59, Special Issue: Planetary Mapping, Elsevier Ltd., pp. 1265-1272, doi:10.1016/j.pss.2010.12.008.

Galluzzi, V., Guzzetta, L., et al., 2016. Geology of the Victoria quadrangle (H02), Mercury. J. of Maps, 12, pp. 227-238, doi:10.1080/17445647.2016.1193777.

Gede, M., Hargitai, H., 2015. Country Movers - an Extraterrestrial Geographical Application. In: Reyes, N.J. (eds.) Cartography beyond the ordinary world Joint ICA Symposium. pp. 178-183.

Gehrke, S., Wählisch, M., et al., 2006. Generation of Topographic and Thematic Planetary Maps Using the Software System "PIMap". In: Mackwell, S., Stansbery, E. (eds.) 37th Annual Lunar and Planetary Science Conference. 
Greeley, R., Batson, R.M., 1990. Planetary Mapping. Cambridge University Press.

GUGK,1988. Map series of Venus based on Venera 16 and Venera 17 observations. GUGK SSSR.

Gwinner, K., Jaumann, R., et al., 2016. The High Resolution Stereo Camera (HRSC) of Mars Express and its approach to science analysis and mapping for Mars and its satellites. In: Planetary and Space Science (PSS), Vol. 126, pp 93-138.

Haber, R.B., McNabb, D.A., 1990. Visualization idioms: A conceptual model for scientific visualization systems. In: Shriver, B., Neilson, G. M. and Rosenblum, L. (ed.) Visualization in Scientific Computing. IEEE Computer Society Press, p 74-93.

Hare, T.M., 2011. Standards-Based Collation Tools for Geospatial Metadata in Support of the Planetary Domain. (Ma. thesis), Northern Arizona University, Flagstaff, AZ, USA.

Hare, T.M., Tanaka, K.L., 2001. Planetary Interactive GIS-on-the-Web Analyzable Database (PIGWAD). ICC 2001, Beijing, China.

Hare, T.M., Kirk, R.L., et al., 2009. Chapter 60: Extraterrestrial GIS. In: Madden, Marguerite (ed.) Manual of Geographic Information Systems: Bethesda, The American Society for Photogrammetry and Remote Sensing, p. 1199-1219.

Hare, T.M., Skinner, J.A., et al., 2011. FGDC Geospatial Metadata for the Planetary Domain, LPSC 2011, \#1608.

Hare, T.M., Skinner, J.A., et al., 2015. Planetary GIS at the U.S. Geological Survey Astrogeology Science Center, $2^{\text {nd }}$ Planetary Data Workshop, held June 8-11, 2015 in Flagstaff, Arizona. LPI No. 1846, 2015, \#7005.

Hare, T.M., Skinner, J.A., Kirk, R.L., 2017, in prep. Cartography Tools. In: Rossi, A.-P., van Gasselt, S. (eds.) Planetary Geology, 540 pp., Springer (Berlin)

Hargitai, H., Shingareva, K.B., 2011. Planetary Nomenclature: a Representation of Human Culture and Alien Landscapes. Advances in Cartography and Giscience. Lecture Notes in Geoinformation and Cartography, 6, (4), pp. 275-288 doi:10.1007/978-3-642-19214-2_18.

Hargitai, H., Li, C., Zhang, Z., et al., 2014. Chinese and Russian Language Equivalents of the IAU Gazetteer of Planetary Nomenclature: an Overview of Planetary Toponym Localization Methods. The Cartographic Journal, doi:10.1179/1743277413

Hargitai, H., Gede, M., Zimbelman, J., et al., 2015. Multilingual Narrative Planetary Maps for Children. In: Robbi, S.C., Madureira Cruz, C.B., Leal de Menezes, P.M. (eds.) Cartography - Maps Connecting the World, Lecture Notes in Geoinformation and Cartography, 17-30, Springer.

Hargitai, H., 2016. Metacatalog of Planetary Surface Features for Multicriteria Evaluation of Surface Evolution: the Integrated Planetary Feature Database. DPS 48/EPSC11 Meeting \#426.23.

Hiller, K., Hauber, E., et al., 1993. Digitale Kartenherstellung der Planetenbildkarten Olympus Mons/Planet Mars. In: Kartograph. Nachrichten, Heft 2 Kirschbaum Verlag, Bonn.

Hu W., Di K., et al., 2013. A new lunar global DEM derived from Chang'E-1 Laser Altimeter data based on crossover adjustment with local topographic constraint. In: Planetary and Space Science (PSS), 87(2013):173-182.

Jaumann, R., Neukum, G., et al., 2007. The high-resolution stereo camera (HRSC) experiment on Mars Express: Instrument aspects and experiment conduct from interplanetary cruise through the nominal mission. In: Planetary and Space Science (PSS) 55, 928-952.

Jin S., 2014. Planetary Geodesy \& Remote Sensing. CRC Press.

Joy, K., Crawford, I., et al., 2011. Moon Zoo: citizen science in lunar exploration. In: Astronomy \& Geophysics, 52(2), 2-10,

doi:10.1111/j.1468-4004.2011.52210.x.
Karachevtseva, I.P., Kokhanov, A.A., et al., 2015. A new Phobos Atlas. International Cartography Conference, Rio de Janeiro 2015, online proceedings, ISBN:978-85-88783-11-9

Karachevtseva, I.P., Kokhanov, A.A., et al., 2016. Modern methodology and new tools for planetary mapping. In: Gartner G., Jobst M., Huang H. (eds.) Progress in Cartography, pp. 207-227, 480 p. Springer, doi:10.1007/978-3-319-19602-2.

Kirk, R., 2016. Planetary Cartography: what, how, and why begin with where. LPSC, \#2151.

Kopal, Z., Carder R.W., 1974. Mapping of the Moon. Springer Science + Business Media Dordrecht.

Kraak, M.-J., Fabrikant, S., 2017. Of maps, cartography and the geography of the International Cartographic Association. Int. J. of Cartography, 23 p. doi:10.1080/23729333.2017.1288535.

Laura, J.R., Hare, T.M., et al., 2017. Towards a Planetary Spatial Data Infrastructure. ISPRS Int. J. Geo-Inf., 6, 181; doi:10.3390/ijgi6060181.

Lehmann, H., Scholten, F., et al.,1997. Mapping a whole planet - the new topographic series 1:200 000 for Mars. ICC 1997, Stockholm, Sweden.

Li C., Liu J., et al., 2010a. The global image of the moon obtained by the Chang'E-1: Data processing and lunar cartography. In: Science China Earth Sciences, 53(8):1091-1102.

Li C., Ren X., et al., 2010b. Laser altimetry data of Chang'E-1 and the global lunar DEM model. In: Science China Earth Sciences, 53(11):1582-1593.

Li C., Ren X., et al., 2015. A new global and high resolution topographic map product of the Moon from Chang'E-2 image data. LPSC 2015, \#1638.

Liu Z., Di K., et al., 2014. High precision landing site mapping and rover localization for Chang'3 mission. In: Science China Physics, Mechanics and Astronomy, 58(1): 019601.

Manaud, N., Boix, O., et al., 2015. Where On Mars? A Web Map Visualisation of the ExoMars 2018 Rover Candidate Landing Sites. EPSC, \#2015-228.

Manaud, N., Rossi, A. P., et al., 2016a. The OpenPlanetary initiative. DPS-EPSC, \#2587836

Manaud, N. Rossi, A.P., et al., 2016b. Summary and Recommendations from the 2015 ESAC Planetary GIS Workshop. LPSC 2016, \#1387.

Manaud, N. Nass, A., et al., 2017. Open PlanetaryMap: Building the first Open Planetary Mapping and Social platform for researchers, educators, storytellers, and the general public. 3rd Planetary Data Workshop 2017, Flagstaff, AZ, USA \#7024.

Marco Figuera, R., Rossi, A.P., et al., 2015. Analyzing Lunar DTMs through web services with EarthServer/PlanetServer-2. ISPRS Commission VI, WG VI/4 meeting, Berlin.

Maslonka, C., 2014. Bestimmung und Kartierung von Stationspunkten der Traverse der Apollo-17-Landestelle auf Basis von Lunar Reconnaissance Orbiter Camera Daten. Ma.-thesis, Beuth Hochschule für Technik Berlin.

Mason, A.C., Hackman, R.J., 1961. Engineer Special Study of the Surface of the Moon. Dep. of Interior, United States Geological Survey.

Mazza, R., 2009. Introduction to Information Visualization. Springer Verlag, London Limited.

Morton, O., 2002. Mapping Mars: Science, Imagination, and the Birth of a World. Picador. New York.

Muller, J.-P., Tao, Y., et al., 2016. EU-FP7-iMARS: Analysis of Mars Multi-Resolution Images Using Auto-Coregistration Data Mining and Crowd Source Techniques: Processed Results - a First Look. In: Int. Archives of the Photogrammetry, Remote Sensing and Spatial 
Information Sciences (ISPRS), 453-58, doi:10.5194/isprs-archivesXLI-B4-453-2016.

Nass, A., van Gasselt S., Jaumann R., 2010. Map Description and Management by Spatial Metadata: Requirements for Digital map legend for Planetary Geological and Geomorphological Mapping. AutoCarto, Symposium on computer-based Cartography and GIScience, \#1457, Orlando, Florida.

Nass, A., van Gasselt, S., et al., 2011. Implementation of cartographic symbols for planetary mapping in geographic information systems. In: Planetary and Space Science (PSS), Vol 59, Special Issue: Planetary Mapping, Elsevier Ltd., pp. 1255-1264, doi:10.1016/j.pss.2010.08.022.

Nass, A., Di., Kaichang, et al., 2017. Planetary Cartography - Activities und Current Status. International Cartography Conference, Washington 2017, online proceedings, \# 419362.

Neugebauer, G., Dorrer, E., 1996. Experimentelle Untersuchungen zur kartographischen Darstellung der Marsoberfläche. In: Kartograph. Nachrichten, Heft 2 Kirschbaum Verlag, Bonn.

NSF, 2012. A vision and strategy for science, engineering, and education: Cyberinfrastructure framework for $21^{\text {st }}$ century. NSF12-113.

Oberst J., Zakharov A., Schulz R. (eds.), 2014. Phobos (special issue). In: Planetary and Space Science (PSS), Vol. 102, 182 p Elsevier.

PCWG (1989), The Planetary Cartography Working Group, Planetary Cartography in the Next Decade: Digital Cartography and Emerging Opportunities, NASA TM 4092.

PDS, 2009. Planetary Data System Standard Reference. Technical Report, Jet Propulsion Laboratory, Institute of Technology, California.

Pędzich, P., Latuszek, K., 2014. Planetary cartography - sample publications, cartographic projections, new challenges. In: Polish Cartographical Review, Vol. 46, No. 4, p.388-396.

Ping J., Huang Q., et al., 2009. Lunar topographic model CLTM-s01 from Chang'E-1 laser altimeter. In: Science in China Series G: Physics, Mechanics and Astronomy, 52(7):1105-1114.

Pondrelli, M., Tanaka, K., et al. (eds.), 2011. Geological Mapping of Mars. Planetary and Space Science (PSS), Vol. 59(11-12), doi: 10.1016/j.pss.2011.07.006.

Portee, D.S.F. 2013. 1961: USGS Astrogeology's First Published Map.

Radebaugh, J., Thomson, B.J., et al., 2017. Obtaining and using Planetary Spatial Data into the future: The role of the Mapping and Planetary Spatial Infrastructure Team (Mapsit). Planetary Science Vision 2050 Workshop 2017, Washington D.C., \#8084.

Roatsch, T., Jaumann, R., et al., 2009. Cartographic Mapping of the Icy Satellites Using ISS and VIMS Data, In: Dougherty, M., Esposito, L., Krimigis, S. (eds.) Saturn from Cassini-Huygens. Springer, pp. 763781.

Roatsch, T., Kersten, E., et al., 2013. High-resolution Vesta Low Altitude Mapping Orbit Atlas derived from Dawn Framing Camera images. In: Planetary and Space Science, Vol 85, 293-298, doi.org/10.1016/j.pss.2013.06.024.

Roatsch, T., Kersten, E., et al., 2016. High-resolution Ceres High Altitude Mapping Orbit Atlas derived from Dawn Framing Camera images. In: Planetary and Space Science, Vol 129, 103-107, doi.org/10.1016/j.pss.2016.05.011.

Rossi, A.P., Cecconi, B., et al., 2015. Planetary GIS and EuroPlanet-RI H2020. EPSC 2015, \#2015-178.

Rossi, A.P., Marco Figuera, R., et al., 2016. Remote Sensing Data Analytics for Planetary Science with Planet/EarthServer. EGU 2016, \#2016-3996.

Rwoley, J., 2007. The wisdom hierarchy: representation of the DIKW hierarchy. Journal of Information Science, 33(2), pp.163-180, doi:10.1177/0165551506070706
Sadler, D.H. (eds.) 1962. Proc. $11^{\text {th }}$ General Assembly of the IAU (Berkeley, 1961). IAU Trans. XIB, Acad. Press, p. 234.

Saiger, P., Wählisch, M., et al., 2005. ArcGIS and GRASS GIS for Planetary Data. 1st Mars Express Science Conference.

Savinykh V.P., Karachevtseva I.P., Konopikhin A.A. (eds.) (2015) The Phobos Atlas Moscow. MIIGAiK, 220 p., 43 maps (In Russian).

Schaber, G.G., 2005. The U.S. Geological Survey Branch of Astrogeology - A Chronology of activities from conception through the end of project Apollo (1960-1973), USGS Open Rep. 2005-1190.

Shevchenko, V., Rodionova, Z., Michael, G., 2016. Lunar and Planetary Cartography in Russia. Springer, doi:10.1007/978-3-31921039-1.

Shingareva, K.B., Krasnopevtseva, B.V., et al., 1992. Atlas of the earthtype planets and their satellites. MIIGAiK.

Shingareva, K.B., Krasnopevsteva, B.V., 2011. A New Version of the Multilingual Glossary of Planetary Cartography. In: Advances in Cartography and GIScience, Vol.2, Series Lecture Notes in Geoinformation and Cartography, pp 289-295.

Shingareva, K.B., Zimbelman, J., et al., 2005. The Realization of ICA Commission Projects on Planetary Cartography. In: Cartographica, 40(4), 105-114, doi:10.3138/3660-4078-55X1-3808.

Shoemaker, E., Hackman, R.J., 1961. Lunar Photogeologic Chart LPC 58. Copernicus, Prototype Chart, USGS, unpublished.

Slipher, E.C., 1962. MEC-1 Map of Mars. United States Air Force.

Snyder, J.P., 1982. Map projections used by the U.S. Geological Survey. U.S. Geological Survey Bulletin 1532.

Snyder, J.P., 1987.Map projections used by the U.S. Geological Survey. U.S. Geological Survey Professional paper1395.

Tanaka, K, Skinner, J., Hare, T., 2011. Planetary Geologic Mapping Handbook - 2011. USGS.

van Gasselt, S., Nass, A., 2011. Planetary mapping: The datamodel`s perspective and GIS framework. In: Planetary and Space Science $(P S S)$, Vol. 59, Special Issue: Planetary Mapping, Elsevier Ltd., pp. 1231-1242, doi:10.1016/j.pss.2010.09.012

Wählisch, M., Willner, K., et al., 2010. A new topographic image atlas of Phobos. In: Earth and Planetary Science Letters 294, 547-553.

Wählisch, M., Stooke, P.J., et al., 2014. Phobos and Deimos cartography. In: Planetary and Space Science (PSS) 102, 60-73.

Ware, C., 2004. Information Visualization - Perception for design. 2nd edition, Elsevier Morgan Kaufmann Publisher, San Francisco, USA.

Whitaker, E.A., Kuiper, G.P., et al., 1963. Rectified Lunar Atlas Supplement Number 2 to the Photographic Lunar Atlas. Aeronaut. Chart Information Center.

Williams, D.A., 2016. NASA`s Planetary Geologic Mapping Program: Overview. Commission IV, ISPRS, WG IV/8 doi:10.5194/isprsarchives-XLI-B4-519-2016.

Willner, K., Oberst, J., et al., 2010. Phobos control point network, rotation, and shape. In: Earth and Planetary Science Letters 294, 541 546.

Willner, K., Shi, X., Oberst, J., 2014. Phobos' shape and topography models. In: Planetary and Space Science (PSS) 102, 51-59.

Wu, B., Li, F., et al., 2014. Topographic Modeling and Analysis of the Landing Site of Chang'E-3 on the Moon. In: Earth and Planetary Science Letters 405(2014): 257-273.

Zastrow, M., 2015. Data visualization: Science on the map. In: Nature, Vol. 519, p. 120 